\title{
A SOFTWARE PACKAGE FOR SIMULATION OF UNSTEADY FLOWS OF THE REACTING GAS IN THE CHANNEL
}

\author{
V.Yu. Gidaspov, Moscow Aviation Institute, Moscow, Russian Federation, \\ gidaspov@mai.ru, \\ V.K. Golubev, Moscow Aviation Institute, Moscow, Russian Federation, \\ sikapul2@yandex.ru,
} N.S. Severina, Moscow Aviation Institute, Moscow, Russian Federation, severina@mai.ru

\begin{abstract}
This paper describes a software package for numerical modelling of the structure of unsteady flows of multicomponent reacting gas with graphic and informational components for resource-intensive phases of computational experiments support. Simulation of the "fine structure" of unsteady flows is achieved because the calculation is carried out at substantially irregular mobile computational mesh, including the fact that the trajectories of strong and weak discontinuities, the parameters of which are calculated by special grid-characteristic algorithms, serve as computational knots; herewith all the gridline intersections are calculated precisely. The designed software package can be used to solve the problems of reacting gas dynamic, which may have practical significance, as well as to illustrate academic courses in physical gas dynamics.
\end{abstract}

Keywords: informational support of gas dynamics problems; informational technologies, grid-characteristic method.

\section{Introduction}

The complexity of the scientific problems, which are solved by the methods of physical and mathematical modelling, and the growing demands to the precision of their solution lead to a significant growth in the amount of data processed during computational experiments. Conducting of the mathematical calculations serves as an alternative and an addition to the physical experiment, allows to reveal the detailed structure of the process which is physically impossible to observe during the experimental research, saves a considerable amount of money and time for conducting natural experiments by anticipating, considerably facilitating and sometimes completely substituting them.

The application area of the created software product is physical gas dynamics. The basis of this work consists of the methods of high precision and efficiency allowing to simulate the gas flow with physical and chemical transformations considering the presence of strong discontinuities (blast waves, contact discontinuities) in the area of the flow. Such flows of the multicomponent reacting gas are realized in many modern technological devices and promising power plants. The solution of multiple tasks, such as, for example, modelling the combustion and detonation processes, demands a considerable amount of computational resources, which now can be provided only by highly productive computing facilities, represented by multiprocessor systems. The major amount of time in these calculations is spent on simulation of the processes connected to the course of chemical 
reactions; meanwhile, the need of computing resources is growing with the increase in the number of components and the number of reactions describing an investigated phenomenon. A principally nonlinear structure of the problems under investigation leads to emerging peculiarities of the solution even if the initial data is smooth, and the desire to investigate the fine structure of unsteady flows of multicomponent reacting gas requires conducting the numerical calculations in detailed differential grids both in time and in space.

Everything mentioned before explains high demands to the sources employed and confirms the urgency to develop a software package with a developed system of graphic and informational support combining the stages of preparation, conducting and maintenance of calculations as well as the necessary means of visualization and analysis of the obtained results. These service components are supposed to facilitate the scholars' duties concerning the setting of the initial data, choosing and comparing/contrasting thermodynamic and kinetic data models, as well as monitoring the computational process.

The elaborated procedure of the numerical modelling can be used to solve the problems of reacting gas dynamics, which have practical significance, and serve as an illustration to the academic courses of physical gas dynamics. This article considers the computational algorithm and the package of software tools for simulating the fine structure of unsteady flows of the multicomponent reacting gas, provides a structure of the package, a description of some of its elements and examples.

\section{Mathematical Model}

Despite the development of the multidimensional methods of simulation, onedimensional models still remain important. Specifically, by comparing numerical and experimental results, they allow to verify the models describing unsteady process of chemical transformations in the gas stage, prepare initial data for multidimensional calculation, conduct full-scale engineering calculations for designing real promising power plants.

Quasi-one-dimensional unsteady flow of the reacting gas in the areas of an uninterrupted flow may be described by a system of partial differential equations, written in its characteristic appearance [1]:

$$
\begin{gathered}
\frac{d x}{d t}=u \pm a: \quad d u \pm \frac{1}{\rho a} d p \pm\left(u a \frac{d \ln F}{d x}+\sum_{i=1}^{N} \frac{\rho_{\gamma_{i}} e_{T}-e_{\gamma_{i}} \rho_{T}}{\rho^{2} a\left(e_{T} \rho_{p}-e_{p} \rho_{T}\right)} W_{i}\right) d t=0, \\
\frac{d x}{d t}=u: \quad d h-\frac{1}{\rho} d p=0, d \gamma_{i}-\frac{1}{\rho} W_{i} d t=0, \quad i=1, \ldots, N .
\end{gathered}
$$

Here, $\rho, u, p, e, h, a$ stand for density, velocity, pressure, specific internal energy and gas enthalpy, sound velocity, respectively; $\gamma_{i}$ is the mol-mass concentration, $N$ is the amount of the components considered, $W_{i}$ is the velocity of the formation of the $i$-th component in the unit of volume as a result of chemical reactions, $F(x)$ is the relation of cross-sectional area from longitudinal coordinate. Lower indexes " $T$ ", " $P$ ", " $\gamma_{i}$ " define partial differentiation with respect to the parameter. The influence of the effects of viscosity, thermal conductivity and diffusion is neglected.

When crossing the blast wave and the contact discontinuity, Rankine - Hugoniot relations, which are the consequence of integral conservation laws, are performed. These 
relations may be written as follows [1]:

$$
\begin{aligned}
\rho_{\mathrm{L}}\left(D-u_{\mathrm{L}}\right) & =\rho_{\mathrm{R}}\left(D-u_{\mathrm{R}}\right) \\
p_{\mathrm{L}}+\rho_{\mathrm{L}}\left(D-u_{\mathrm{L}}\right)^{2} & =p_{\mathrm{R}}+\rho_{\mathrm{R}}\left(D-u_{\mathrm{R}}\right)^{2}, \\
\rho_{\mathrm{L}}\left(D-u_{\mathrm{L}}\right)\left(h_{\mathrm{L}}+\frac{\left(D-u_{\mathrm{L}}\right)^{2}}{2}\right) & =\rho_{\mathrm{R}}\left(D-u_{\mathrm{R}}\right)\left(h_{\mathrm{R}}+\frac{\left(D-u_{\mathrm{R}}\right)^{2}}{2}\right) .
\end{aligned}
$$

Parameters on the left and on the right of the gap are indicated with the indexes " $L$ " and " $R$ " respectively. In case of a blast wave: $\mathrm{D}$ is a velocity of the wave, the concentrations at the transition through the blast wave remain unchanged: $\gamma_{\mathrm{L} i}=\gamma_{\mathrm{R} i}$. In case of a contact discontinuity: $D=u_{\mathrm{L}}=u_{\mathrm{R}}$; thus, $p_{\mathrm{L}}=p_{\mathrm{R}}$, the change of the other units is arbitrary.

Thermodynamic properties of the reacting gas are described by the model of the multicomponent paragon gas under the assumptions about the equilibrium occupancy of energy levels, corresponding to all the inner degrees of freedom of molecules and atoms [2]. In this case, Gibbs' thermodynamic potential has the following form:

$$
G(p, T, \bar{\gamma})=\sum_{i=1}^{N} \gamma_{i}\left[R T \ln \left(p \gamma_{i} / p_{0} \sum_{j=1}^{N} \gamma_{j}\right)+G_{i}^{0}(T)\right]
$$

Here, $p_{0}$ is standard pressure, $G_{i}^{0}(T)$ is the temperature part of standard molar Gibbs potentials of separate components [2]. Reference in literature gives polynomial approximative formulae for reduced standard potential $\Phi_{i}^{0}(T)$, connected with $G_{i}^{0}(T)$ through the formula:

$$
G_{i}^{0}(T)=\Delta_{f} H_{i}^{0}\left(T_{0}\right)-\left[h_{i}^{0}\left(T_{0}\right)-h_{i}^{0}(0)\right]-T \Phi_{i}^{0}(T),
$$

where $h_{i}^{0}(0)$ is the standard enthalpy $h(T)$ at absolute zero, $h_{i}^{0}\left(T_{0}\right)$ is the standard enthalpy $h(T)$ at $T_{0}=298,15 \mathrm{~K}$. For assigning $\Phi_{i}^{0}(x)\left(x=10^{-4} T\right)$, we use in our research the same polynomials as in the reference book [2]:

$$
\Phi_{i}^{0}(x)=\varphi_{0}+\varphi_{\ln } \ln (x)+\varphi_{-2} x^{-2}+\varphi_{-1} x^{-1}+\varphi_{1} x+\varphi_{2} x^{2}+\varphi_{3} x^{3} .
$$

Here, $\varphi_{k}, k=\ln ,-2, \ldots, 3$ are the numerical coefficients, individual for each substance. Other thermodynamic values used in mathematic modelling are expressed through Gibbs potential and its partial derivatives. In case of voluntary mechanism from $N_{r}$ reversible chemical reactions of the forms [3, 4]:

$$
\begin{gathered}
\sum_{i=1}^{N} \vec{\nu}_{i}^{(r)} M_{i} \Leftrightarrow \sum_{i=1}^{N} \overleftarrow{\nu}_{i}^{(r)} M_{i}, r=1,2, \ldots, N_{r} \\
W_{i}=\sum_{r=1}^{N_{R}}\left(\overleftarrow{\nu}_{i}^{(r)}-\vec{\nu}_{i}^{(r)}\right)\left(\vec{K}^{(r)} \prod_{j=1}^{N}\left(\rho \gamma_{j}\right)^{\vec{\nu}_{j}^{(r)}}-\overleftarrow{K}^{(r)} \prod_{j=1}^{N}\left(\rho \gamma_{j}\right)^{\overleftarrow{\nu}_{j}^{(r)}}\right)
\end{gathered}
$$

Here, $M_{i}$ is a symbol of substance $i, \stackrel{\leftarrow}{\vec{v}}_{i}^{(r)}$ are stoichiometric coefficients, the velocity constants of direct $\vec{K}^{(r)}$ and reverse $\overleftarrow{K}^{(r)}$ reactions are connected through the equilibrium 
constant [2-5]. For the approximation of temperature dependence on velocity constants of direct reactions, we use the generalized Arrhenius formula [3]:

$$
\vec{K}(T)=A T^{n} \exp \left(-\frac{E}{T}\right) .
$$

$A, n, E$ are some constants, individual for each reaction. The choice of the velocity constant in reverse direction depends on whether the reaction is reversible or not. In case of reversible reaction the velocity constant may be chosen through the equilibrium constant as well as by the Arrhenius formula.

\section{Informational Demands of the Subject Area and the Problems of Data Modelling}

Developing informational support for resourse-demanding problems of gas dynamics presumes active use of database technologies for storage, manipulation, analytical and graphical processing of significant numeric content [6].

The mathematical model defines a set of requirements to a software package under development. The employed model of thermodynamics and chemical kinetics sets the structure of database of thermodynamic properties of substances and chemical reactions. In particular, every substance is defined by a number of individual qualities, such as molecular weight, the matrix of its structure, formation enthalpy and polynomial coefficients of Gibbs potential for corresponding temperature range (in real calculations there are usually no more than two of them) and so on. To describe a chemical reaction it is necessary to know the patterns of its course in time. For approximation of the temperature dependence on velocity constants of direct reactions we use the generalized Arrhenius formula. In this model only the third(or less)-order reactions are considered [3-5], the velocity of each passing reaction may be described by several $A, n, E$ combinations from different reference sources. The velocity of the reverse reaction, depending on the mechanism, may be calculated from the equilibrium condition [2, 5], as well as by the Arrhenius formula.

To illustrate this, we will examine, for example, Riemann problem in the channel closed on both sides [7-10]. This problem investigated the modes of the expansion of a shock wave, formed in result of the decomposition of a discontinuity on the boundary of highand low-pressure chambers. The parameters of the high-pressure chamber $(0 \leq x \leq 0,5)$, filled with helium: $T_{\mathrm{HPC}}=3000 \mathrm{~K}$, pressure $P_{\mathrm{HPC}}=10^{6} \mathrm{~Pa}$. The low-pressure chamber $(0,5 \leq x \leq 1)$ was filled with stoichiometric hydrogen-aerial mixture with $P_{\mathrm{LPC}}=101325 \mathrm{~Pa}, T_{\mathrm{LPC}}=298,15 \mathrm{~K}$, combustion products of which included 7 components $\left(\mathrm{H}_{2}, \mathrm{OH}, \mathrm{H}_{2} \mathrm{O}, \mathrm{O}_{2}, \mathrm{~N}_{2}, \mathrm{H}, \mathrm{O}\right)$. When modelling processes in the low-pressure chamber, chemical transformations may be taken into account. Modern mechanisms of hydrogen combustion in the air include from 8 to 50 reversible stages [3-5]. The particular feature of this problem is that the chambers are filled with gases with different characteristics, and there are different physical and chemical processes passing in them.

On the Fig. 1 there is a time-base sweep of the flow, from which it may be seen that in a result of the decomposition of a discontinuity the shock wave and the contact discontinuity spread to the right, while the ring of a rarefaction wave spreads to the left. During the reporting period shock waves (bold solid lines), contact discontinuities (solid line) and characteristics (big dotted line with points) repeatedly interact with each other 
and with the closed ends of the channel. Gas trajectories (small dotted line) are used as additional field nodes. From the time-base sweep it is evident how the gas accelerates and changes its course, how the shock waves reverberate from the walls and interact with each other, forming additional shock waves and characteristics.

It is necessary to notice here that the methods, used in modelling, with allocation of all discontinuities, leads to a non-standard format of output data and, as a consequence, to non-standard ways of its processing and mapping. Special algorithms process all the intersections of grid lines, which come out to a precise coordinate, and it needs to be executed correctly in the process of visualization. The visualization system must possess the full set of facilities of standard graphic systems for preparing high-quality graphics for colored and black-and-white publications: line styles, axes inscriptions, axes layout and so on.

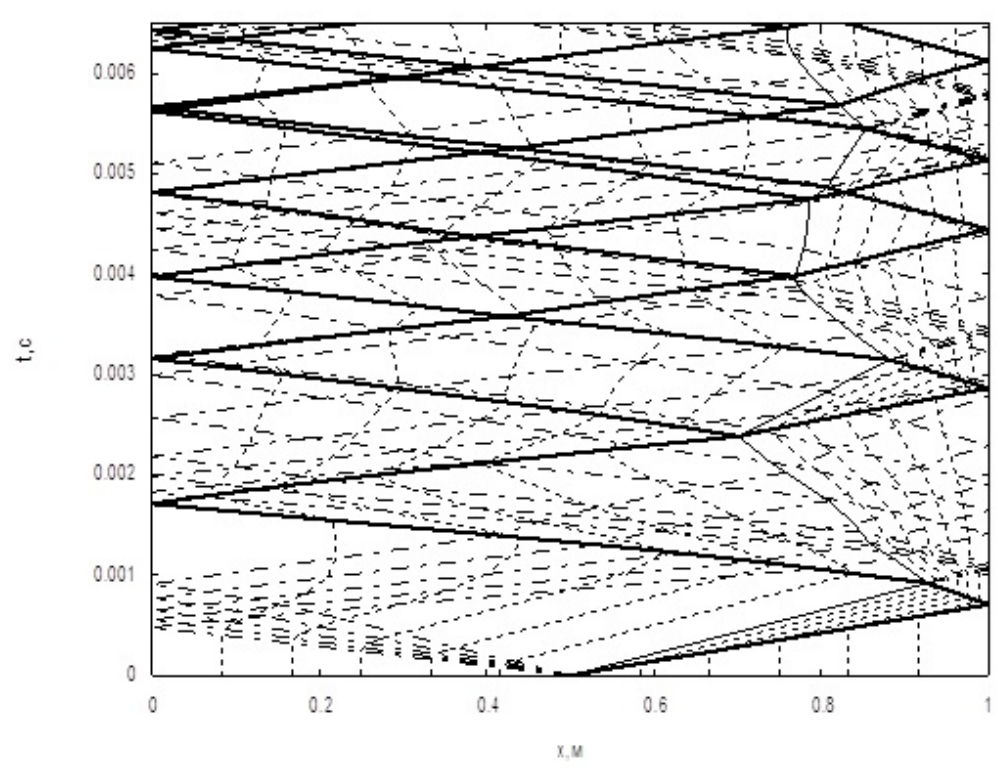

Fig. 1. Time-base sweep: shock wave - bold solid line, contact discontinuity - thin solid line, characteristics - large dotted line with points, gas trajectory - small dotted line

It is necessary to concentrate the solution of these problems within the centralized control of the data and the computational modules, which provides the connection between the user and the package as a whole (interface component), as well as between separate subsystems inside the package (stream component). The description of the evolved data classes allows to specify their semantic content, to set necessary connections and to form submodels. Metadata is necessary to develop an invariant (conceptual) plan of the package database, steady to external presentation.

\section{Computational Algorithm}

To solve the system of equations given in section 1, we use in this work the gridcharacteristic method, described in details in [7-10]. The method is marching in time, which coincides with the concept of geometric parallelism because the layer is a loosely coupled group, which may be decomposed into sublayers. However, it is necessary to consider the peculiarities of this method when parallelizing: supporting points, the number 
of which is variable, may be situated not only in the previous layer, but also on the extracted discontinuities; new points may appear on the layer in the calculation process and the intersection of grid lines may be realized.

For parallelizing, we employed the MPI (Message Passing Interface) standard. This interface standard is the most widely used for data exchange in parallel programming. The idea of the parallel algorithm is that the calculation of the points of a new temporal required level is conducted simultaneously. Each process must calculate new points so that the processes were independent, if possible. To provide the independence of the processes, the following rules were employed:

1. The previous calculating level is divided into subgroups, the number of which must be equal to a number of available processes.

2. The point of the discontinuous type (shock wave, contact discontinuity) cannot be placed on the boundary of a subgroup. These points should not be situated closer than three points of the indissoluble type (gas trajectory, wall, fixed point, characteristic point) from the boundary. As a result, the number of points in the groups is different.

We can denote the following objects that are necessary for the points computing process, working simultaneously: a group of points from the previous level, information about the number of levels, march in time, the number of fragmentation points, the number of calculated points and the information about whether the march fragmentation was executed or not. Unfortunately, all the parameters except for the group of points of the previous layer and the march in time are dynamic. As a result, it is necessary to inform the processes about the change in these parameters after the calculation of each point. This peculiarity affects substantially the efficiency of the algorithm.

Thus, the algorithm for the calculation of the temporal layer includes the following stages:

1. Form groups of points from the previous layer according to the rules mentioned earlier.

2. Send the objects necessary for calculation to all the processes.

3. Synchronize the mentioned dynamic parameters with the other processes after the calculation of each point of the process.

4. After all the processes finish the calculation of their group, combine the results obtained in the new layer in time.

\section{The Architecture of the Complex}

Basing on the analysis of the subject area peculiarities, we developed a structure of the system of informational support of the problems of physical gas dynamics (Fig. 2).

Mention the main characteristics of the system:

1. The user has the opportunity of offline editing of the database of thermodynamic characteristics and chemical reactions to modify the stored information as well as to create concerted "mixtures" and "kinetic mechanisms", which may be used for further calculations.

2. The interface of configurations editing and computational module launching provides the initial data setting for numerical modelling, which include: the configuration of computational area and boundary conditions; dividing of the computational area into subareas with different initial gas-dynamic values, thermodynamic characteristics 
and passing physical processes, controlling parameters for the computational module; characteristics of the employed methods of numerical modelling. There is a provided opportunity to store standard problems and configurations. The interface provides an access to a database of the results of numerical modelling, a revision of the results and, if necessary, a restart of computational module.

3. The databases for storage of the results of calculations have a dynamic structure that provides the storage of the results of the calculation of the problems, which may have a completely different structure of output data. To achieve this, we developed a format of the configuration file with the results (including the description of stored physical values), according to which a corresponding element of the database is formed. The database provides storage, import and export of graphic and textual material of the user connected to the conducted calculation.

4. The calculation of visualization subsystem takes into account the specific character of each problem. Namely: hyperbolicity of the problem -- the number of steps in marching variable usually surpasses substantially (by many orders) the number of cells of differential grid; there are different types of grid lines, the number of grid lines is variable - they may appear and disappear; the number of the visualized parameters is variable. The following types of graphs are realized: parametrization (functions of parameters) with arbitrary (present in the file with results) value of marching variable; change of arbitrary parameter (or set of parameters) along the arbitrary grid line and with a fixed value of non-marching variable, "temporal" sweep of the process. For vivid presentation of the results, the function of grid lines subsampling is realized. The visualization subsystem allows both colored and black-and-white form of graphic material presentation and provides the export of data.

5. The users function within informational system with different access permissions, controlled by the system administrator, and these access permissions may vary substantially when operating on different elements of the system. For example, the modification of the database of the thermodynamic characteristics of the substances is available only for privileged users.

The purpose of general interface is to combine all modules of the programming complex in one application to provide the user with fast access to any of them. Within the united user interface, the user can proceed to one of three specific interfaces: gas mixtures and kinetic mechanisms editing interface, computational module interface and results visualization interface. The work with configuration editing interface starts with opening an xml-file of the project, which describes available gas mixtures and kinetic mechanisms. The user will have a list with a short description of all mixtures, which have been tested. The line will be colored in red if the file with the mixture does not exist or is impossible to open. Yellow color signifies that the file is empty or does not contain necessary marking. Green color tells that the file is analyzed successfully. After the mixture is chosen, the user will be suggested to choose the file with kinetic mechanisms related to the chosen mixture. When both files with settings are chosen, the configuration editing form for calculation launching will be available.

For initial data setting we created a specialize interface. The type of the problems under solution presupposes a piecewise continuous character of the flow parameters distribution in calculation area in the initial moment of time, which allows to set calculation area in the form of special points and subareas, which boundaries are marked with these points, and then to define the parameters of the flow in each of subareas. The user creates a list 


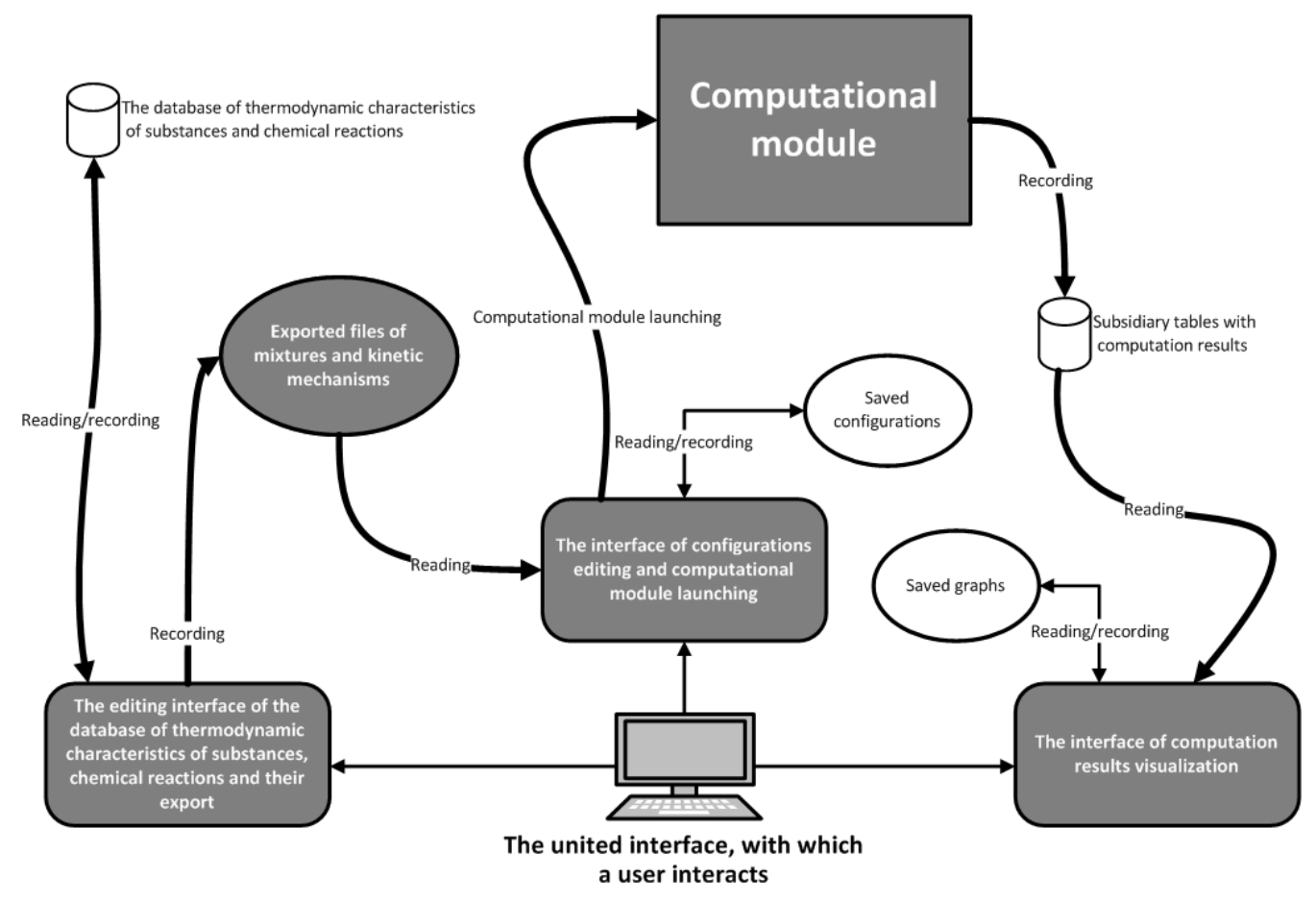

Fig. 2. The architecture of the complex

of special points, sets the type of each point, its coordinate and velocity. Then the user describes the parameters of subareas. The following types of special points are provided: "entrance boundary", "exit boundary", "combustion chamber", "exit to the atmosphere", "left wall", "right wall", "decomposition of the discontinuity", "extreme characteristic of the wave ring", "fixed point", "shock wave". The description of a subarea includes:

1) flow parameters (pressure, velocity, temperature);

2) field point type (characteristic $\left(\mathrm{C}_{+}, \mathrm{C}_{-}, \mathrm{C}_{0}\right)$, wall, contact discontinuity, shock wave, gas trajectory, characteristic of discontinuity, field fixed point);

3) the number of points of division in the area;

4) the strategy of the filling of the subarea with the knots of differential grid (slide knots or fixed knots);

5) type of gas (inert, reacting, equilibrium reacting); 6) ratio of mixture (for each subarea different ratio is possible. The program connects to a database and receives a list of all set chemical mixtures. The user chooses the type of the mixture and sets a molar fraction of each substance in the mixture).

Besides the setting of the computational area, there is an opportunity to set controlling parameters for computation:

1) launching type (from the beginning or from a control point);

2) interpolation type (linear or quadratic);

3) frequency of dropping of the control layer to the file;

4) frequency of dropping of the layers to graphic files;

5) type of problem (about the piston, decomposition of discontinuity in the closed area, about the denotation wave, etc.). 
For storage, retrieval and preliminary processing of numerical results of the computation a rather fast built-in relational partitioned database SQLite is used. HandIndex and Parameters relations limit the table workspace. Every sequence in HandIndex contains information about a computation layer (point ID, time, marching in time). Parametric detalisation of the stored point (coordinate, pressure, temperature and so on) are contained in corresponding $(1: N)$ sequences of Parameters. The absence of reading block allows the visualization module to detune the graphics at any stage of computation.

Visualization interface allows the user to assign the settings of graph drawing or choose among those created before. When launching the interface, a number of queries to a base are executed to receive general information about its content, namely a list with types of points for the first-type graph, a list of times of the layers for the second graph and a list of points coordinates for the third.

Graph visualization module is a specially developed application that implements the main opportunities for representing two-dimensional graphs. The application was developed in $\mathrm{C}++$, OpenGL specification was chosen as a graphic library. Graphic library development from scratch allows to enlarge the functional and to insert the opportunities that cannot be achieved by standard means of drawing. One of such opportunities is filtration or rarefication of the represented lines. The filtration partially throws away a part of a represented graph, so that the user could discern separate lines. One more characteristic feature of the visualization module is a built-in command line that makes it possible to measure the parameters of graph representation, such as size and color of the represented lines, axes inscriptions, the frequency of grid lines, filtration parameters. There is also an opportunity to save the current graph in a standard raster picture format (Fig. 1).

\section{Conclusion}

This work describes a software package for numerical simulation of quasi-onedimensional non-steady flows of reacting gas, including informational support and visualization subsystems. The specific feature of the developed package is its pronounced module structure, it contains four weakly dependent components: the database containing thermodynamic and kinetic data, computational module with human-system interface, database for storage of the results of numerical simulation, results visualization system. All the components of the package may function independently and may be used by different software products. The further development of the software product may imply including additional modules for calculation of steady and non-steady flows of multi-component gas mixtures to the computational outline, as well as adding a subsystem for conducting and controlling educational laboratory works in physical and gas dynamics.

Acknowledgements. The research is conducted with partial support of State Assignment № 721 and RFBR (project № 15-01-07964)

\section{References}

1. Computational Aspects of Solving Problems Concerning Environmental Protection: Collection of Scientific Works. Moscow, MAI, 1988. (in Russian) 
2. Gurvich L.V., Medvedev V.A., Veits I.V. Thermodynamic Properties of Individual Substances: Reference Book. Moscow, Nauka, 1982. (in Russian)

3. Kondratiev V.N. Velocity Constants for Gas-Phase Chemical Reactions (Reference Book). Moscow, Nauka, 1970. (in Russian)

4. Combustion Chemistry. N.Y., Springer, 1984.

5. Gidaspov V.Yu., Severina N.S. Elementary Models and Computational Algorithms of Phisical Gas Dynamics. Thermodynamics and Chemical Kinetics. Moscow, Factorial, 2014. (in Russian)

6. Marasanov A.M., Rotanina M.V. The Design of Informational Support of Gas-Dynamic Package Using a Relational DBMS. Computational Technologies. Collection of Scientific Works, 1993, vol. 2, no. 6, pp. 38-47. (in Russian)

7. Gidaspov V.Yu., Pirumov U.G., Severina N.S. Mathematical Modelling of Quasi-OneDimensional Unsteady Flows of Reacting Gas with an Arbitrary Number of Interacting Discontinuities. MAI Bulletin, 2008, vol. 15, no. 5, pp. 83-94. (in Russian)

8. Gidaspov V.Yu., Severina N.S. Elementary Models and Computational Algorithms of Physical Gas Gynamics. One-Dimensional Unsteady Flows. Moscow, Factorial, 2015. (in Russian)

9. Gidaspov V.Yu, Severina N.S. Numerical Simulation of Experiments to Determine Ignition Delays Behind Incident Shock Wave. Combustion Explosion and Shock Waves, 2013, vol. 49, no. 4, pp. 409-417. DOI: 10.1134/S0010508213040035

10. Gidaspov V.Yu., Severina N.S. Numerical Simulation of the Fine Structure of a Cylindrical Detonation Wave in a Hydrogen-Air Combustible Mixture. High Temperature, 2015, vol. 53, no. 4, pp. 526-530. DOI: 10.1134/S0018151X15040124

Received April 1, 2016

УДК 519.6

DOI: $10.14529 / \mathrm{mmp} 160308$

\section{ПРОГРАММНЫЙ КОМПЛЕКС ДЛЯ МОДЕЛИРОВАНИЯ НЕСТАЦИОНАРНЫХ ТЕЧЕНИЙ РЕАГИРУЮЩЕГО ГАЗА В КАНАЛАХ}

\section{В.Ю. Гидаспов, В.К. Голубев, Н.С. Северина}

Описывается комплекс программных средств численного моделирования тонкой структуры нестационарных течений многокомпонентного реагирующего газа с графическими и информационными компонентами поддержки ресурсоемких этапов вычислительных экспериментов. Моделирование «тонкой структуры» нестационарного течения достигается за счет того, что расчет ведется на существенно нерегулярной подвижной разностной сетке, в том числе расчетными узлами являются траектории сильных и слабых разрывов, параметры в которых рассчитываются по специальным сеточно-характеристическим алгоритмам, при этом точно рассчитываются все пересечения сеточных линий. Разработанный комплекс программ может использоваться для решения задач динамики реагирующего газа, имеющих прикладное значение, а также в качестве иллюстратора учебных курсов по физической газовой динамике.

Ключевые слова: информационная поддержка задач газовой динамики; информационные технологии; сеточно-характеристический метод.

Работа выполнена при частичной поддержке Госзадания КП № 721 и РФФИ (проект № 15-01-07964) 


\section{Литература}

1. Вычислительные аспекты решения задач охраны окружающей среды: сборник научных трудов / Под ред. У.Г. Пирумова. - М.: МАИ, 1988. - 68 с.

2. Термодинамические свойства индивидуальных веществ: справочное издание в 4-х т. / Л.В. Гурвич, И.В. Вейц, В.А. Медведев и др. - М.: Наука, 1982. - 344 с.

3. Кондратьев, В.Н. Константы скорости газофазных химических реакций / В.Н. Кондратьев. - М.: Наука, 1970. - 352 с.

4. Химия горения / Под ред. У. Гардинера, мл. - М.: Мир, 1988. - 464 с.

5. Гидаспов, В.Ю. Элементарные модели и вычислительные алгоритмы физической газовой динамики. Термодинамика и химическая кинетика / В.Ю. Гидаспов, Н.С. Северина. - М.: Факториал, 2014. - 85 с.

6. Марасанов, А.М. Проектирование информационной поддержки газодинамического пакета с помощью СУБД реляционного типа / А.М. Марасанов, М.В. Ротанина // Вычислительные технологии. - 1993. - Т. 2, № 6. - С. 38-47.

7. Гидаспов, В.Ю. Математическое моделирование квазиодномерных нестационарных течений реагирующего газа с произвольным числом взаимодействующих разрывов / В.Ю. Гидаспов, У.Г. Пирумов, Н.С. Северина // Вестник МАИ. - 2008. - Т. 15, № 5. C. $83-94$.

8. Гидаспов, В.Ю. Элементарные модели и вычислительные алгоритмы физической газовой динамики. Одномерные нестационарные течения. / В.Ю. Гидаспов, Н.С. Северина. - М.: Факториал, 2015. - 85 с.

9. Гидаспов, В.Ю. Численное моделирование экспериментов по определению времени задержки воспламенения за падающими ударными волнами / В.Ю. Гидаспов, Н.С. Северина // Физика горения и взрыва. - 2013. - Т. 49, № 4. - С. 31-40.

10. Гидаспов, В.Ю. Численное моделирование тонкой структуры цилиндрической детонационной волны в водородно-воздушной горючей смеси / В.Ю. Гидаспов, Н.С. Северина // Теплофизика высоких температур. - 2015. - Т. 53, № 4. - С. 556-560.

Владимир Юрьевич Гидаспов, кандидат физико-математических наук, доцент, кафедра «Вычислительная математика и программирование», Московский авиационный институт (г. Москва, Российская Федерация), gidaspov@mai.ru.

Виктор Константинович Голубев, аспирант, кафедра «Вычислительная математика и программирование», Московский авиационный институт (г. Москва, Российская Федерация), sikapul2@yandex.ru.

Наталья Сергеевна Северина, кандидат физико-математических наук, доцент, кафедра «Вычислительная математика и программирование», Московский авиационный институт (г. Москва, Российская Федерация), severina@mai.ru.

Поступила в редакиию 1 апреля 2016 г. 